11 ـ ماجدة بدر أحمد إبر اهيم، دراسة تحليلية لتقييم الأداء البيئي للمباني الذكية، رسالة ماجستير، كلبة الهندسة، جامعة

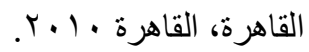

Y ب محمد عباس الزعفراني، التصميم المناخي للمنشآت المعمارية ـ مدخل كمى لتقييم الأداء المناخي للغلاف

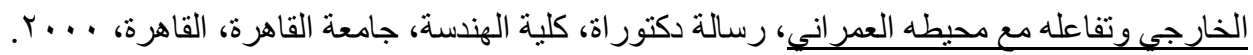

.Dell' Isola Alphonse, Value Engineering in the Construction Industry, 1982 . Ir

Dell' Isola Alphonse, Value Engineering - Practical Applications for Design, . I

Construction, Maintenance and Operations, 1997.

Zimmerman and Glen Hart, Value Engineering - A Practical Approach for Owners, . 10 Designers and Constructors, 1997.

Charles J. Kibert, Sustainable Construction - Green Building Desigen and Delivery, . 17 Second Edition, John Wiley \& Sons, New Jersey, 2008. 


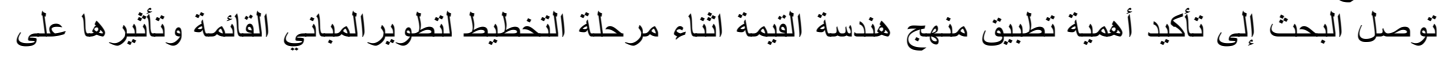

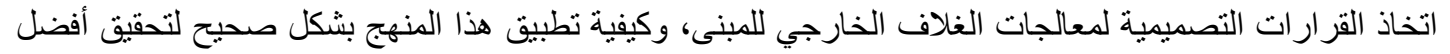

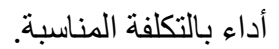

التأكيد على المقدرة الفائقة لدفهوم هندسة القيمة على الاختيار بين البدائل اعتماداً على التحليل المقارن للمستوى القيمي

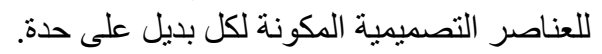

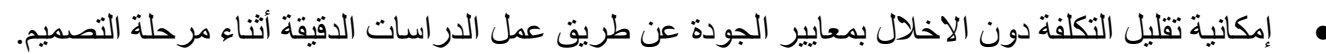

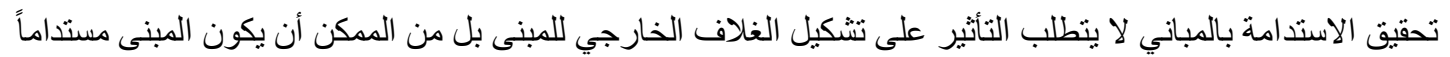

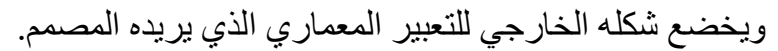

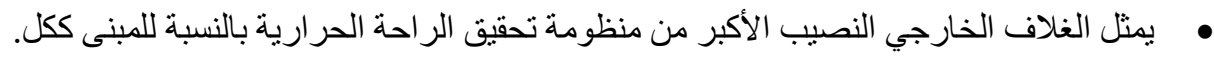
ان تحقيق الاستدامة لا يقتصر على المبانى الجديدة فحسب بل يمتد ليشمل المبانى القائمة.

1 - م. التوصيات

• ضرورة وجود فريق عمل هندسة القيمة أثناء مر احل التخطيط لتطوير المباني القائمة والقيام بعمل الدراسة القيمية للمشروع. حث المعمارين على إعطاء الفرصة والوقت المناسب لتطبيق منهج هندسة القيمة علي مشرو عاتهم، للرفع من جودة المشروعات. التأكيد على أن تطبيق منهج هندسة القيمة يعتبر أحد مر احل العمل بالمشروع المعاك المعاري.

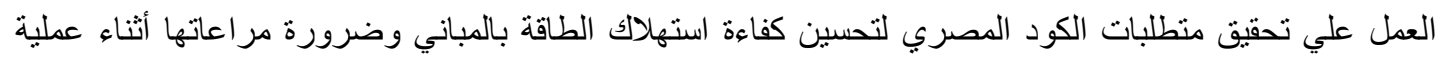
التصميج. العمل على إيجاد بدائل للمعالجات المختلفة التي من شأنها أن تقلل في التكلفة مع الأخذ في الاعتبار المعايير

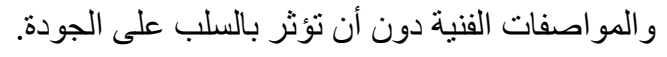

'. العبد العزيز سليمان اليوسفي، إدارة القيمة ـ المفهوم والأسلوب، مكتبة الملك فهر الوطنية، الطبعة الثالثة،

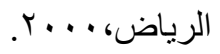
r. مهاب حامد مطر ـ. الهندسة القيمية ـ الإدارة الهندية بين الجودة والتكلفة. مركز تطوير الأداء والتتمية ـ الطبعة

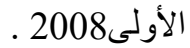

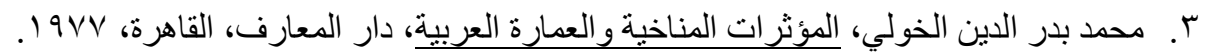

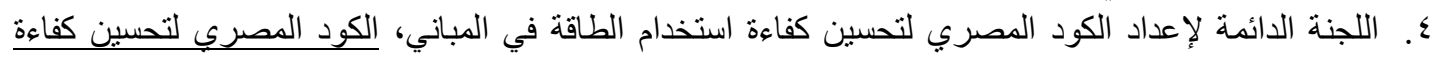

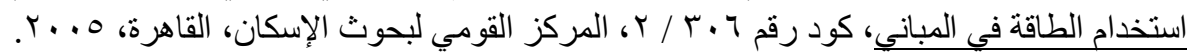
๑. محمد سعيد مصيلحي، الهندسة القيمية نحو منهج تو افقي قيمي لمشروعات الإسكان الحكومي بمصر من من خلال

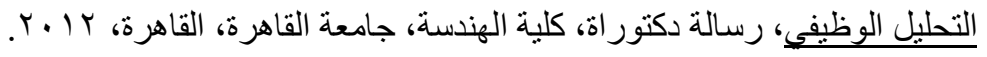

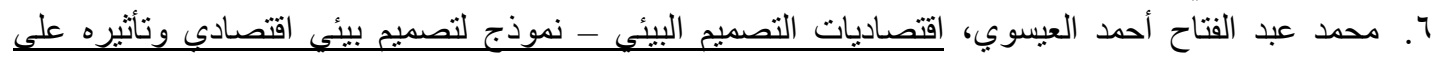

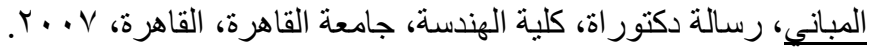
V. أحمد إبراهيم عثمان، منهج إدارة القيمة بين رفع الجودة وخفض التكاليف ـ دراسة في تطبيق المنهج على مرحلة

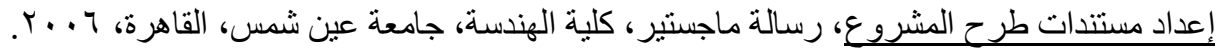

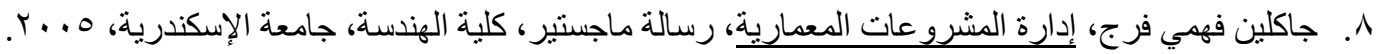
9 . علي عباس يحيى العلفي، الاستدامة كمدخل لترشيد الطاقة في المباني باستخدام الطاقة المتجددة ــ در اسة ميدانية

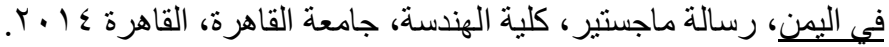

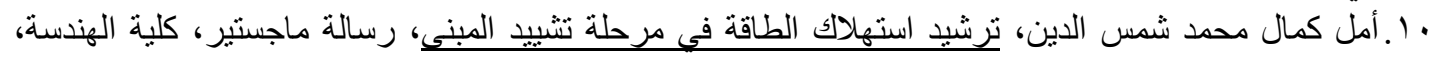

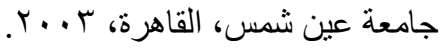


ب- ساب تكاليف بدائل المعالجات

يتم حساب التكاليف الابتدائية اللازمة لبدائل المعالجات شاملة كافة لوازم التنفيذ من توريد المو اد الخام ــ العمالة اللازمة للتنفيذ - تكاليف النقل والمعدات.... إلخ. يتم احتساب الوفر في استهلاك الطاقة اللازمة لأحمال التبريد لكل بديل من البدائل عن طريق المعادلة التالية

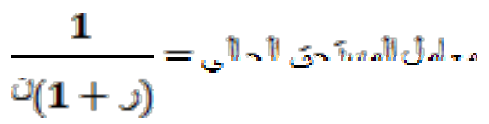

هالمستحق الحالي (ح): هو قيمة المبلغ المطلوب الآن لكي يمكن الإنفاق على التكاليف الدورية والتكاليف الجارية في

• المستحق المستقبلي (م): هو قيمة المبلغ الذي سوف يتم إنفاقه في المستقبل على التكاليف الدورية و التكاليف الجارية

وتكلفة استهلاك الطاقة.

• معدل التضخم (ر): هو نسبة الاستثمار أو الزيادة السنوية في تكلفة السلع أو الخدمات والتي يحددها البنك المركزي

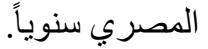

• عدد السنوات (ن): هو الزمن من عمر المادة أو البديل الذي نحتاج فيه إلى إنفاق التكاليف الدورية و التكاليف الجارية.

يتم احتساب التكلفة الكلية عن طريق حساب التكلفة الابتدائية بالاضافة الى قيمة استهلاك الطاقة على فترة عمر . ب سنة

بداية من العام الحالي.

\begin{tabular}{|c|c|c|c|}
\hline التكلفة الكلية & 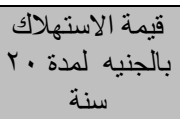 & التكلفة الابتدائية & البدائل \\
\hline $117 \varepsilon \varepsilon \wedge .7$ & $117 \leq \leq \wedge .7$ & - & الاساسي \\
\hline $97 \ldots \leqslant V$ & $\wedge \wedge 0 \ldots \leqslant V$ & vo.... & الاول \\
\hline 11TOY077 & 11.71077 & $r q \ldots$. & الثاني \\
\hline $1 \cdot V \wedge V \leqslant Y q$ & $1 \cdot r \leq V \leq r q$ & $0 \leq \ldots$ & الثالث \\
\hline 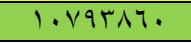 & 1. Кчт人⿻. & $\varepsilon r \ldots$ & الر ابع \\
\hline
\end{tabular}

التكلفة الكلية لبدائل المعالجات لمدة · r سنة (المصدر الباحث)

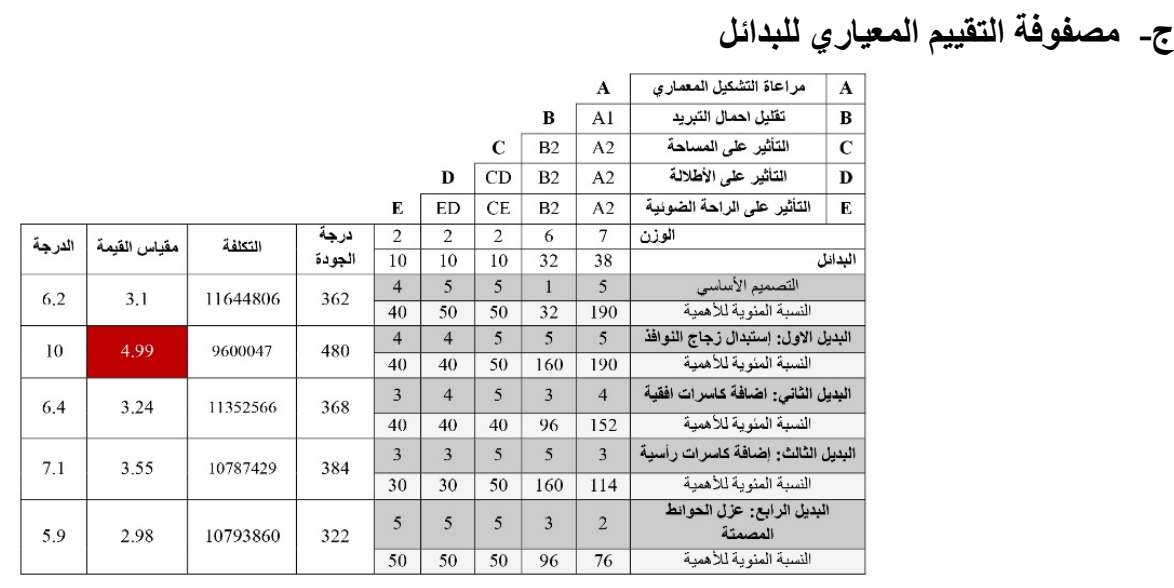

مصفوفة التقييم المعياري (المصدر الباحث)

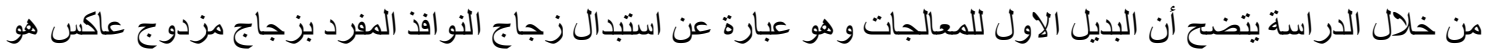
الأعلى قيمة بين البدائل الأخرى و هو الخيار الأمثل لمعالجة ترشيد استهلاك الطاقة في المبنى محل الدراسة.

1 , 1 م مرحلة إعداد التقرير المبئي

يتم إعداد التقرير المبئي للار اسة ويكون مفصلاً لثرح المشروع و المشكلة والأفكار المطروحة لحلها، مع اقتر اح البديل الامثل. 
1 ا 1 , ـ مرحلة التقويم والاختيار

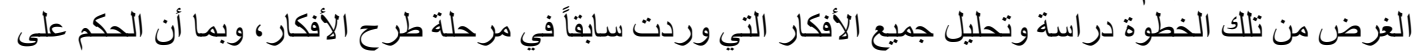

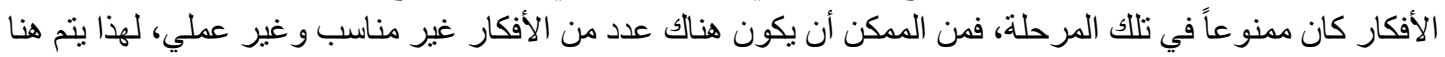

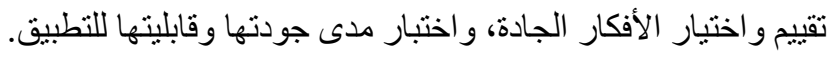

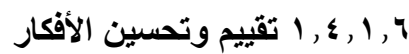

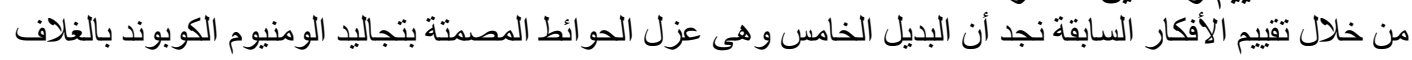

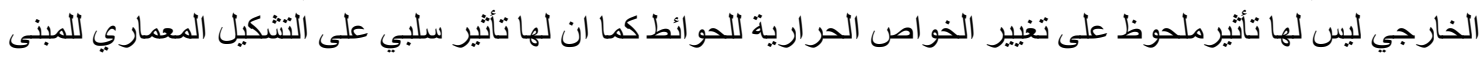

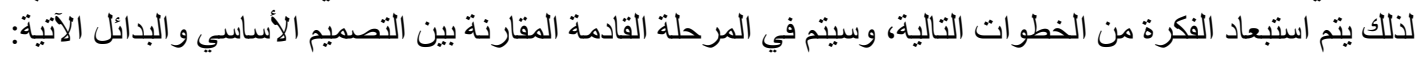

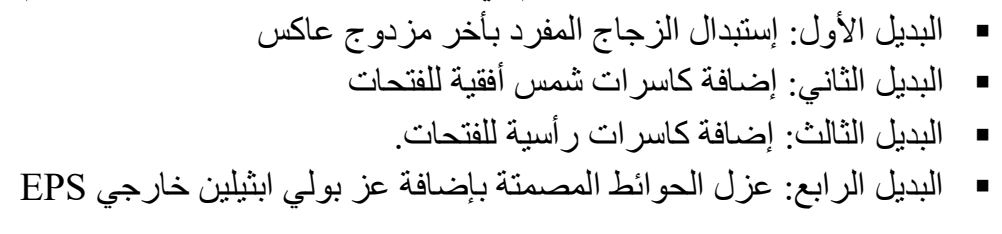

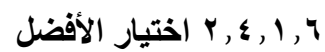

يتم المفاضلة بين بدائل المعالجات للغيلاف الفيل الخارجي المفترحة، وتتم هنا المفاضلة عن طريق حساب التكاليف لبدائل المعالجات، ومصفوفة التقييم المعياري.

أ- - حساب الوفر في استهلاك الطاقة.

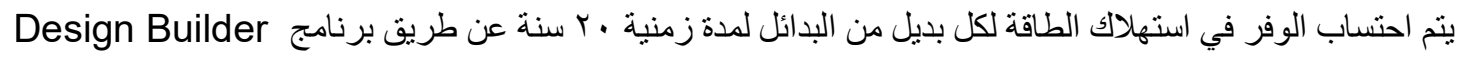

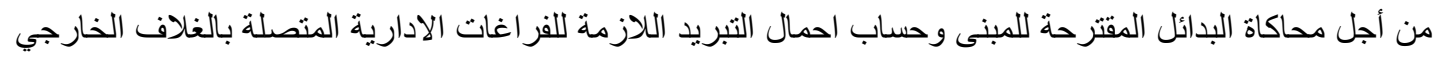
للو اجهة الجنوبية الغربية.

\begin{tabular}{|c|c|c|c|c|}
\hline التوفبر & قيمة الوفر & 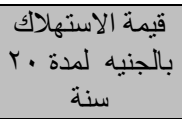 & 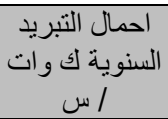 & البدائل \\
\hline$\%$ & - & $117 \leqslant \leqslant \wedge .7$ & ¿qr $\{r \leqslant$ & الاستسيمي \\
\hline$\%$ \% & TVQ VYOA & $110 \ldots \leqslant v$ & rVO..r & الاول \\
\hline$\%$ & ONYTrG & 11.74074 & ETAVOY & الثاني \\
\hline$\%)$ & 1 TYVYVT & $1 . r \leqslant V \leqslant Y q$ & $\varepsilon r \leqslant T \mid r$ & الثالث \\
\hline$\% 11$ & $1 Y \lambda .9 \leqslant 7$ & 1. זדז1. & $\varepsilon r q 1 \leqslant V$ & الرابع الر ابع \\
\hline
\end{tabular}

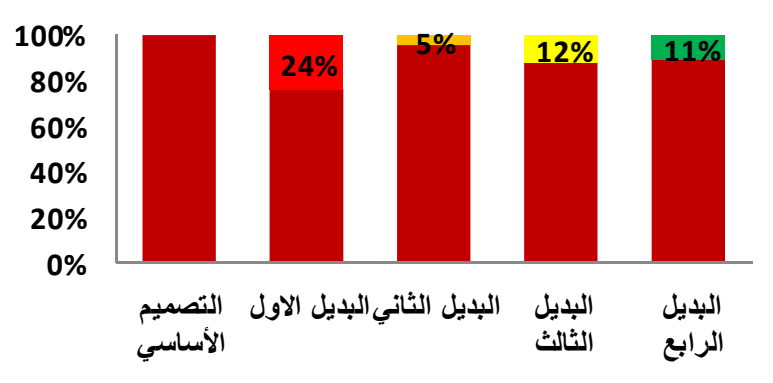

نسبة توفير البائل لاستهلاك الطاقة (الدصدر الباحث) 


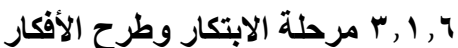

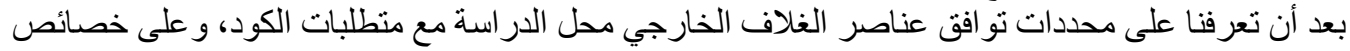

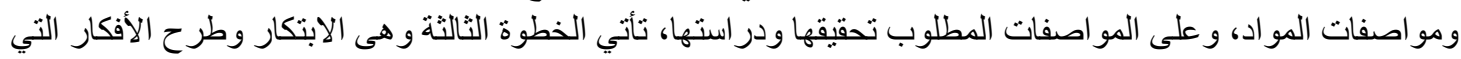

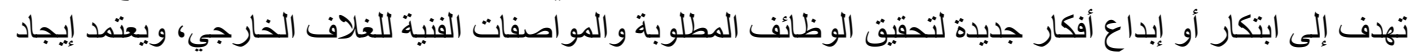

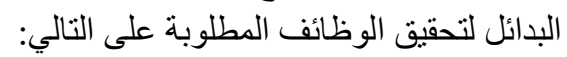

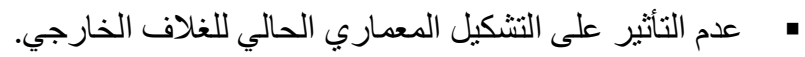

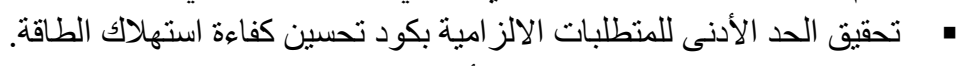

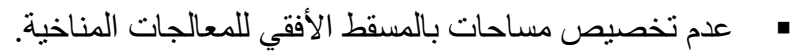
• تو افق معالجات الغلاف الخارجي مع الاشتر اطات البنائية للمبنى.

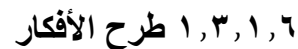

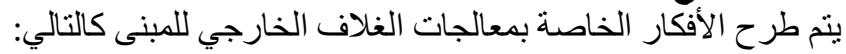

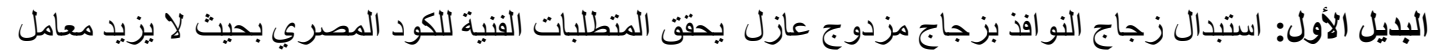

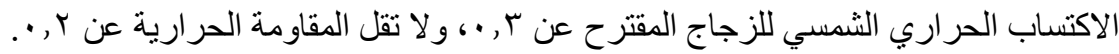

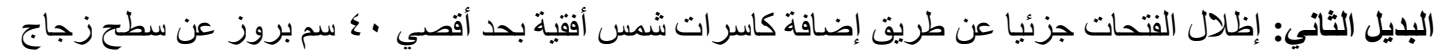

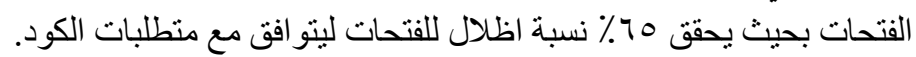

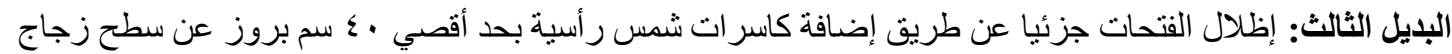

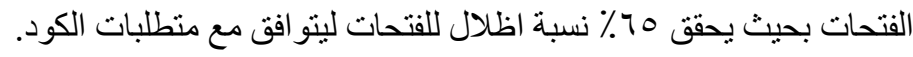

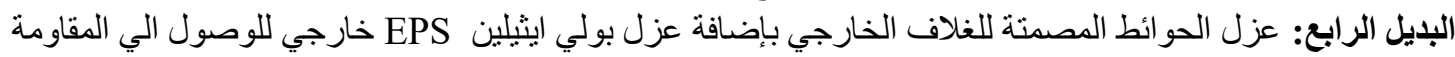
الحر ارية المطلوبة طبقا للكود. البديل الخامس: عزل الجرلة الحوائط المصمتة للغلاف الخارجي باضافة تجاليد الومنيوم الكوبوند خارجي للوصول الي المقاومة الحر ارية المطلوبة طبقا للكود.

\begin{tabular}{|c|c|c|c|}
\hline الممبزات و العبوب & & الفكرة & البديل \\
\hline تحقيق متطلبات الكود التشكيل المعماري للمبنى. & - & 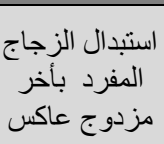 & الأول \\
\hline 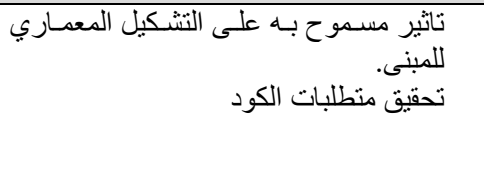 & - & 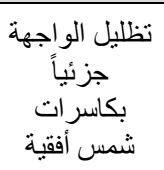 & 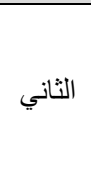 \\
\hline 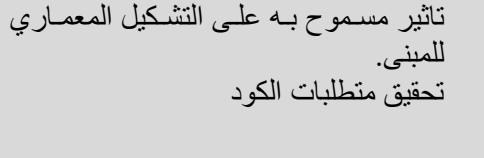 & - & شظليل الو اجهة & 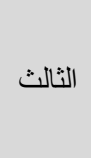 \\
\hline 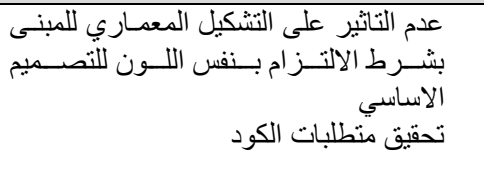 & - & اضافة عزل بولين ايثلين EPS & الر ابع ل \\
\hline 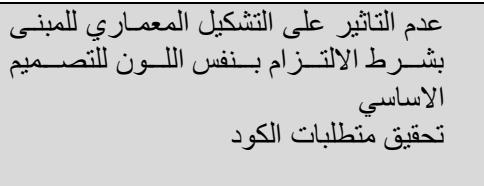 & " & $\begin{array}{l}\text { الضافة تجاليد الكومنيوم } \\
\text { خارجي }\end{array}$ & الخامس \\
\hline
\end{tabular}

تسجيل الافكار وعرض المميزات والعيوب لبدائل المعالجات (المصدر الباحث) 
• عدم السماح بالتغيير في مساحة الدور أو مساحة الفراغات الداخلية بعمل واجهة مزدوجة أو بعمل بروزات

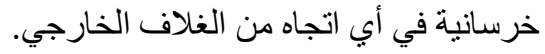

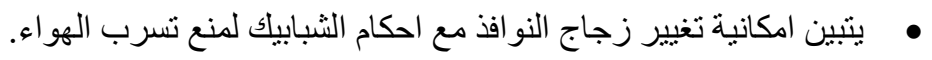

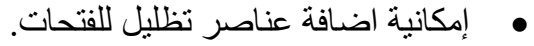

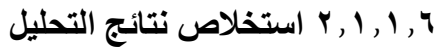
من خلال در اسة التصميم الابتدائي للمبنى نستنتج ما يلي:

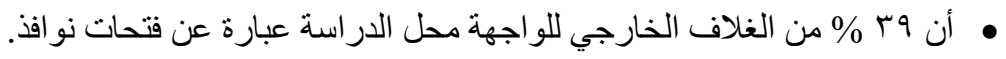

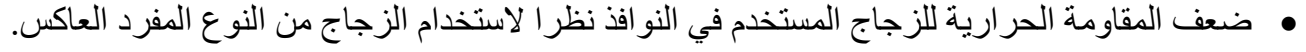

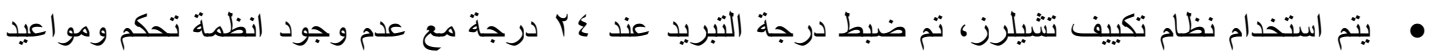

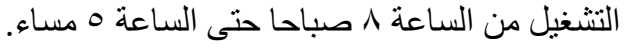

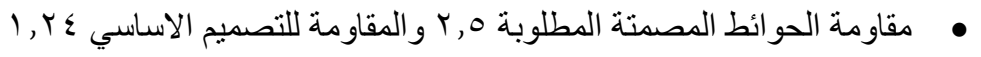

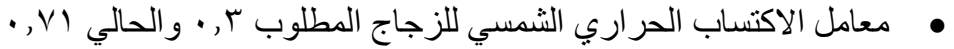

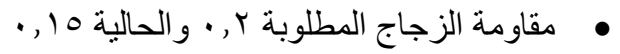

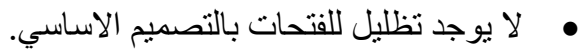

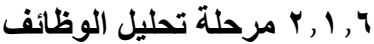
وتبدأ هذه المرحلة بتحديد الوظائف، ثم تصنيف الوظائف، ثم ربط الوظائف بمخطط FAST، وتنتهي باختيار الوظائف التي يمكن تحسينها.

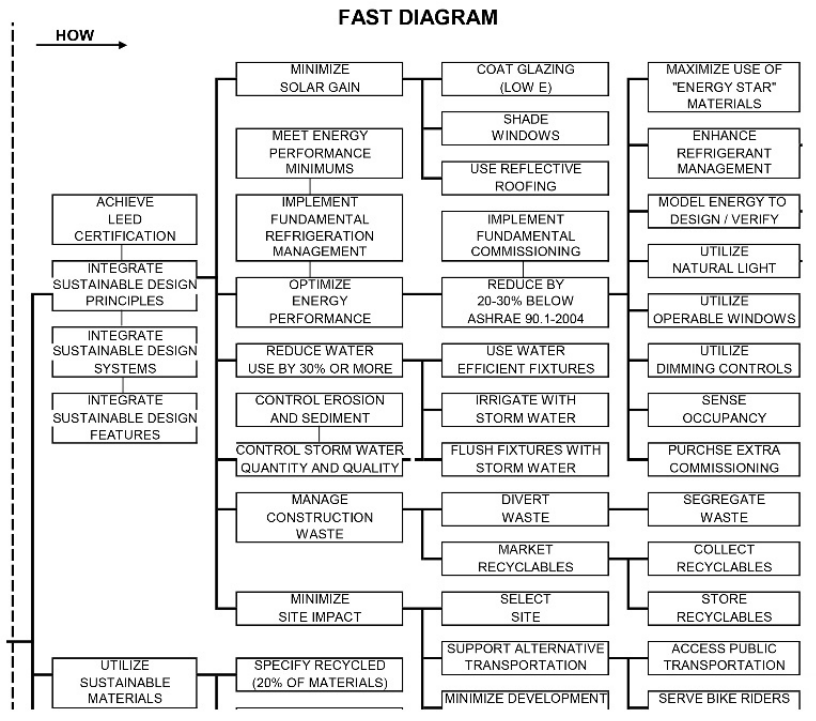




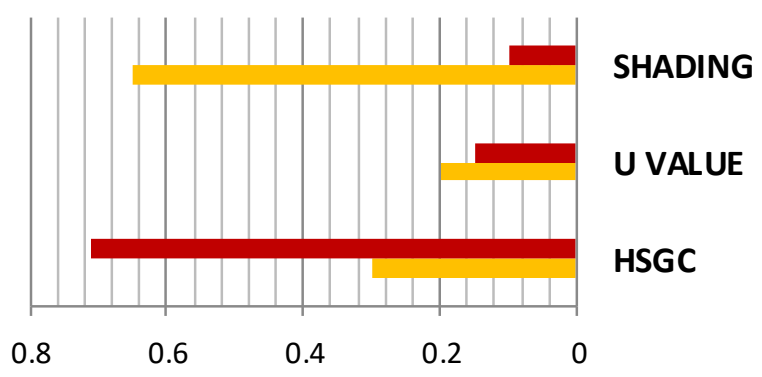

تحليل القتحات بالنسبة لمتطلبات الكود (المصدر الباحث)

د ـ احمال التبريد

تم استخدام برنامج Design Builder من أجل محاكاة الوضع القائم للمبنى وحساب احمال التبريد اللازمة للفر اغات

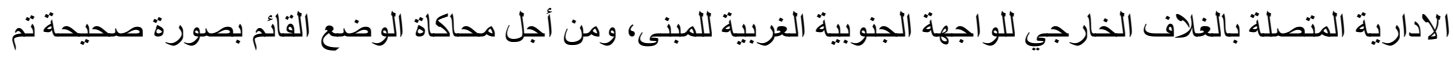
ادخال البيانات الاتية

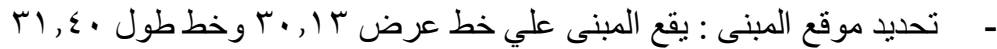

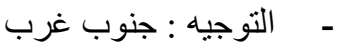
-

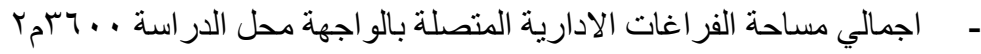

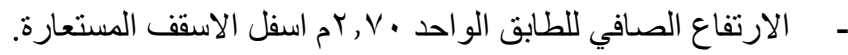

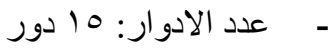
-

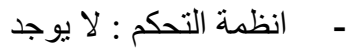

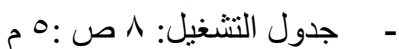
-

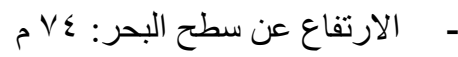

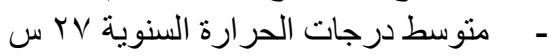

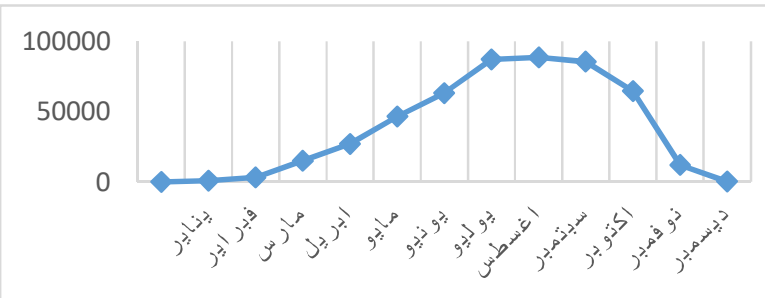

احمال التبريد الثهرية للفراغات الادارية (الباحث باستخدام برنامج (إم) Design Builder)

يتبين من نتائج تحليل الاحمال للتصميم الاساسي للمبنى حيث تصل احمال التبريد السنوية . . ع ؟ ؟ وح ك و ات / س هـ دراسة التشكيل المعماري والاشتراطات البنائية.

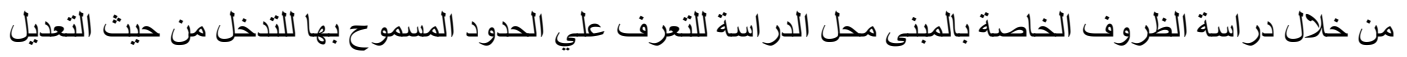
أو الإضافة تبين الأتي: • اورورة الحفاظ على الثكيل المعماري للمبنى. 


\begin{tabular}{|c|c|c|}
\hline \multicolumn{3}{|c|}{ نسبة الحوانط بالواجهة الجنوبية الغربية : 1ل \% \% } \\
\hline طريقة الحساب & التوصيف & الخصائص \\
\hline 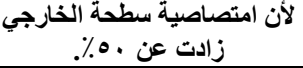 & داكن & 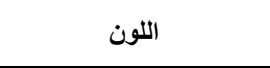 \\
\hline 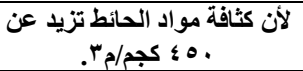 & إنثاء ثقيل & ثقل الإنشاء \\
\hline \multicolumn{2}{|l|}{$r, 0}$. & المقاومة الحرارية المطلوبة \\
\hline \multicolumn{3}{|c|}{ يتم احتساب المقاومة الحرارية الكلية للحائط عن طريق الجمع الجبري لمقاومات } \\
\hline \multicolumn{2}{|c|}{ المقاومة } & الطبقات \\
\hline \multicolumn{2}{|l|}{$\cdot, 1 \mathrm{~V}$} & المقاومة السطحية الداخلية \\
\hline \multicolumn{2}{|l|}{$\cdot, \mathrm{r} \wedge$} & 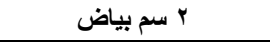 \\
\hline \multicolumn{2}{|l|}{ • } & 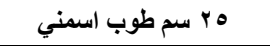 \\
\hline \multicolumn{2}{|l|}{$\cdot, \mathrm{Y} \wedge$} & 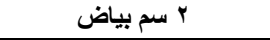 \\
\hline \multicolumn{2}{|l|}{$\cdot, 11$} & المقاومة السطحية الخارجية \\
\hline \multicolumn{3}{|c|}{ النتائج النهائية لحساب المقاومة الحرارية الموجودة بحوائط الواجهة الجنوبية } \\
\hline $1, r \leq$ & & المقاومة الحرارية الإجمالية \\
\hline
\end{tabular}

تحليل الحوائط بالنسبة لمتطلبات الكود (المصدر الباحث)

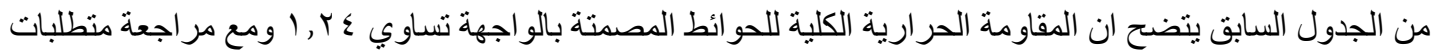

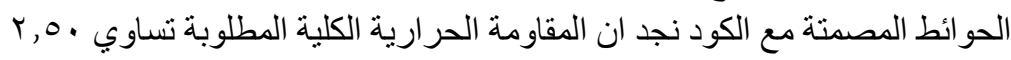

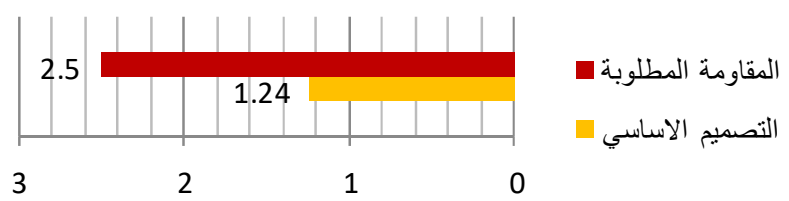

التصميم الاساسي للحوائط المصمتة بالنسبة لمتطلبات الكود (المصدر الباحث)

ثنانيا: تحليل القتحات

من خلال دراسة خو اص الفتحات الموجودة بالتصميم الاساسي للمبنى ومقارنتها بمتطلبات الكود نجد انه يجب الا يزيد

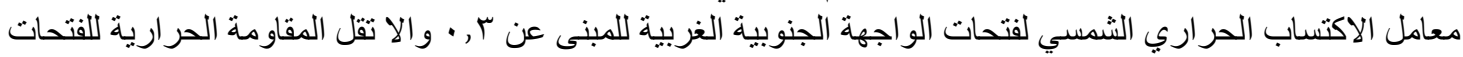

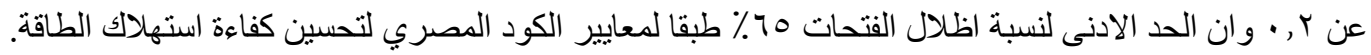

\begin{tabular}{|c|c|c|}
\hline \multicolumn{3}{|c|}{ 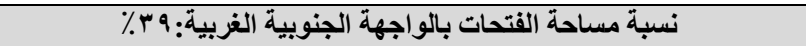 } \\
\hline القيمة المطلوبة & التصميم الاساسي & الخصائص \\
\hline$\cdot, r$ & $\cdot, \mathrm{VI}$ & معامل الاكتساب الحراري الشمسي \\
\hline$\cdot, Y$. & $\cdot, 10$ & المقاومة الحرارية \\
\hline$\% 70$ & لا يوجد & نسبة الاظلال \\
\hline
\end{tabular}




\section{ج - تحليل المسقط الافقي للاور المتكرر والواجهة الجنوبي الغربية}

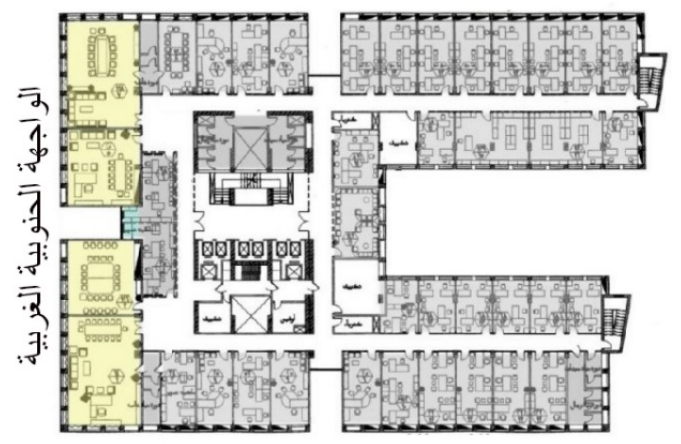

المسقط الافقي للاور المتكرر للمبنى

يتضح من المسقط الافقي ان نسبة الفر اغات الادر ارية المطلوب توفير راحة حر اريـة بها تشـغل نسبة . . ( ٪ مـن مسـاحة الواجهة الجنوبية الغربيةً.

\begin{tabular}{|c|c|}
\hline 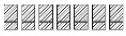 & 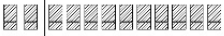 \\
\hline 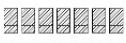 & 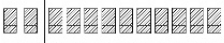 \\
\hline 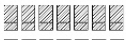 & 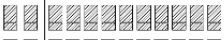 \\
\hline 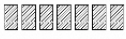 & 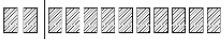 \\
\hline 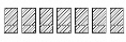 & 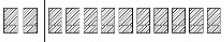 \\
\hline 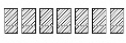 & 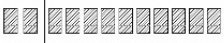 \\
\hline 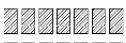 & 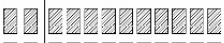 \\
\hline 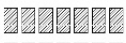 & 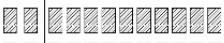 \\
\hline 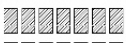 & 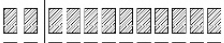 \\
\hline 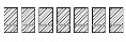 & 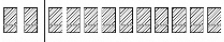 \\
\hline 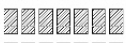 & 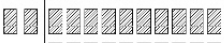 \\
\hline 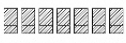 & 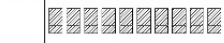 \\
\hline 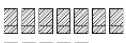 & 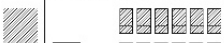 \\
\hline 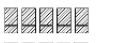 & - \\
\hline 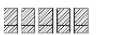 & 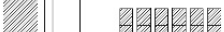 \\
\hline
\end{tabular}

الواجهة الجنوبية الغربية للمبنى (المصدر الباحث)

فيما يلي تحليل عناصر الو اجهة محل الدر اسة طبقا لمعايير الكود المصري لتحسين كفاءة استهلاك الطاقة في المباني لتحديد

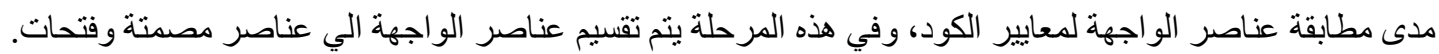

\begin{tabular}{|c|c|c|}
\hline \multicolumn{3}{|c|}{ المساحة الإجمالية للواجهة الجنوبية الغربية: ، ج اY مجY } \\
\hline النسبة من مساحة الواجهة & المساحة & العنصر \\
\hline$\% 71$ & rolTוV,t. & حوائط مصمتة \\
\hline$\% r q$ & $r_{\rho} \wedge \leqslant Y_{,} \leqslant$. & فتحات \\
\hline
\end{tabular}




\section{T. الدراسة التطبيقية}

تقوم الدر اسة التطبيقية على تحليل نموذج لمعالجات الو اجهة الجنوبية الغربية بمبنى وز ارة الكهرباء و الطاقة المتجددة.

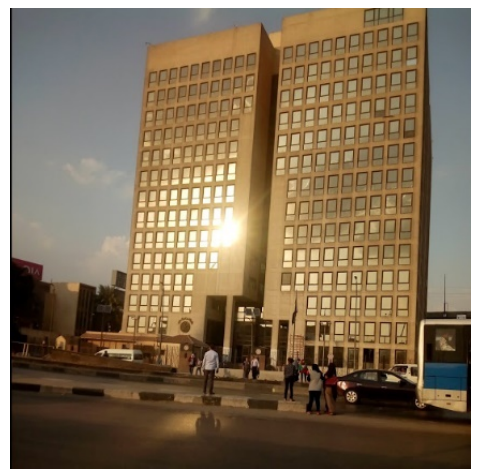

مبنى وزارة الكهرباء والطاقة المتجددة (المصدر الباحث)

يتكون المبنى من دور بدروم ودور ارضي وميز انين با ا دور متكرر ودور سطح، تبلغ اجمالي المساحة المبنية للمبنى

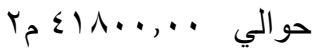

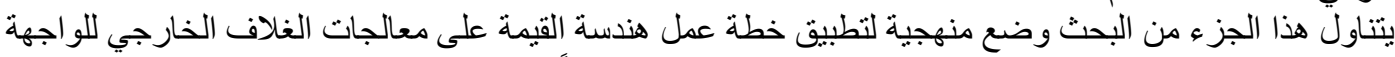

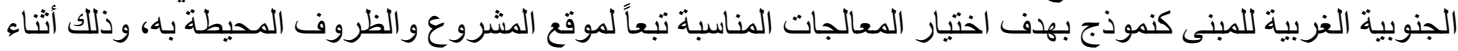

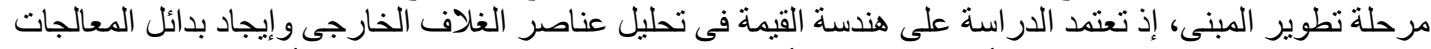

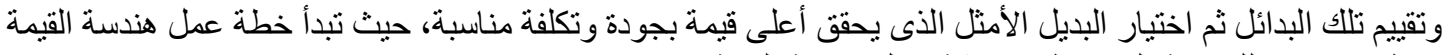
بخطوة الإعداد للار اسة تليها خطوة ورشة الئة عمل هندسة القيمة.

1 1 تطبيق خطوات منهج هندسة القيمة على الحالة الاراسية تمر خطة العمل بعدة مر احل تبدأ بمرحلة المعلومات إلى إلى أن تتنهي بالتقرير الابتدائي للار اسة.

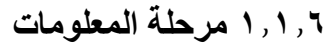

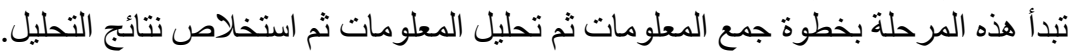
(1, 1, 1, 1, 1, جمع المعلومات أـ موقع المشروع: يقع المشروع بإقليم الدلتا والقاهرة تبعاً لتقسيم الأقاليم المناخية بجمهورية مصر العربية المحددة

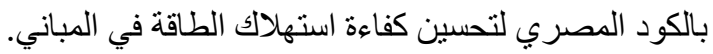

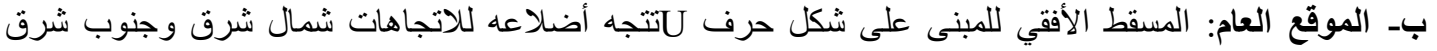

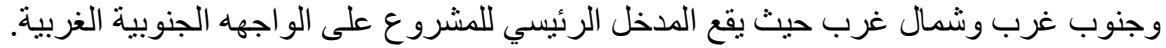

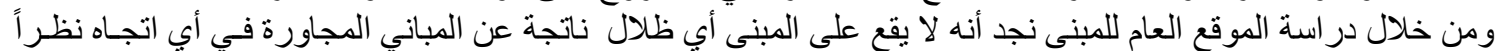

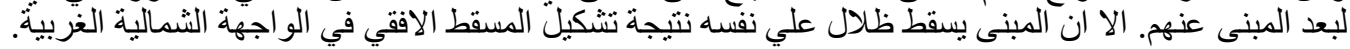

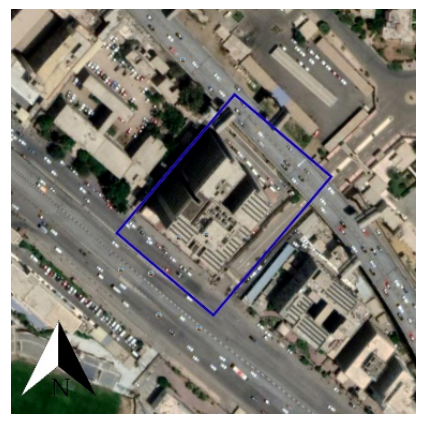

الموقع العام لمبنى وزارة الكهرباء والطاقة المتجددة (المصدر الباحث) 
ج- معالجات الفتحات الخارجية: معالجة الفتحات الخارجية لها دور أساسي في تقليل الحمل الحر اري النافذ لداخل المبنى

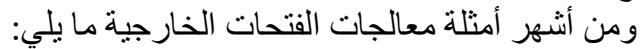

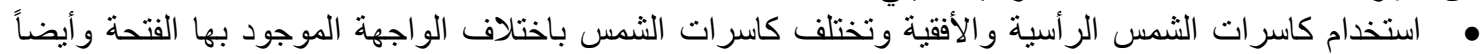

يختلف تصميم الكاسرة حسب رؤية المصمم بشرط أن تحقق الهدف الأساسي في منع أثعة الثمس الثمس من النفاذ لاخل الفراغ.

استخدام نوع زجاج بمو اصفات عالية لتقليل الاحمال الحرارية المنتقلة عبر الفتحات.
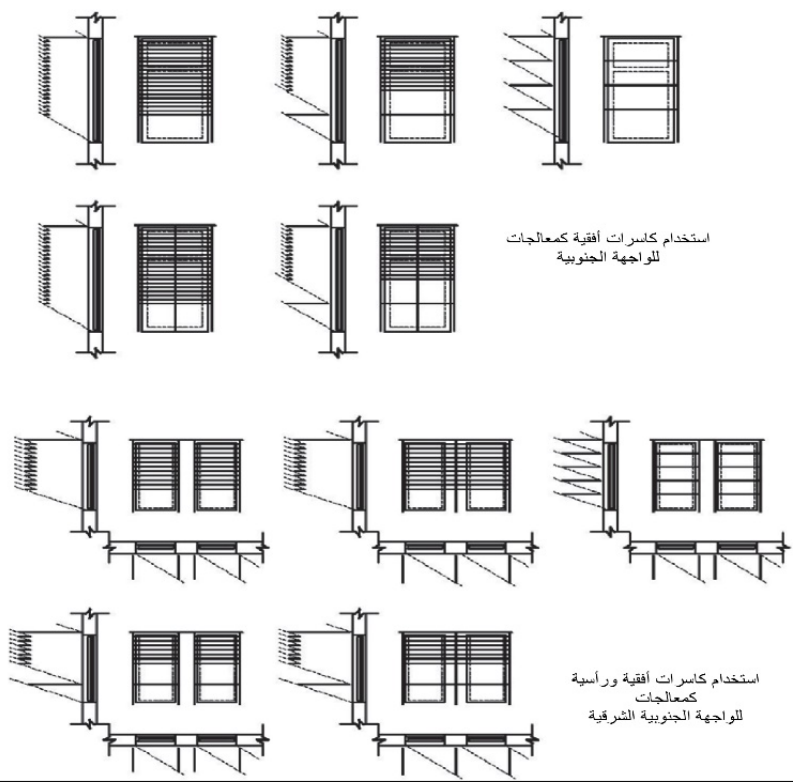

\section{وسائل معالجات الفتحات}

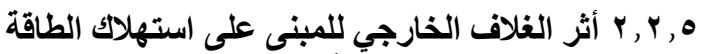

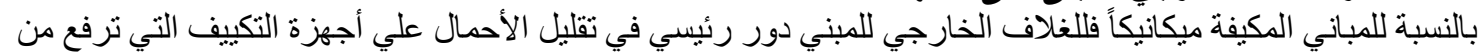

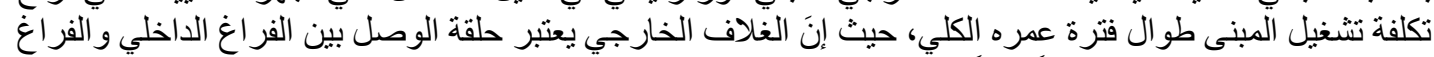

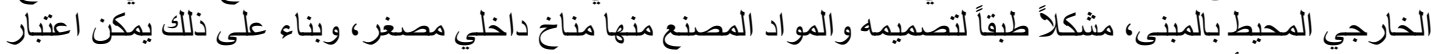

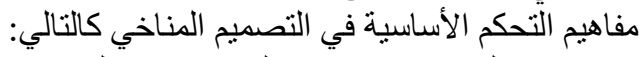

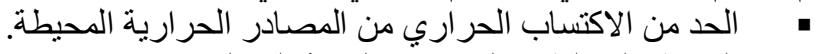

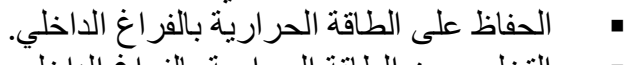

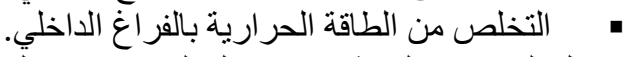

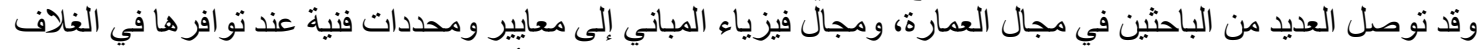

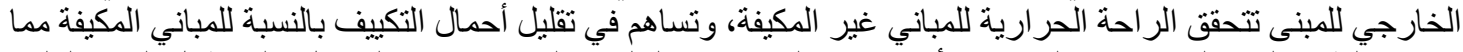

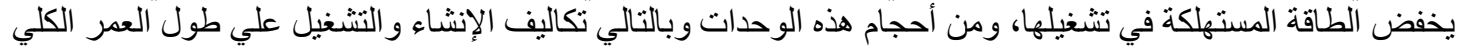

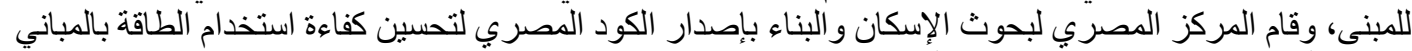

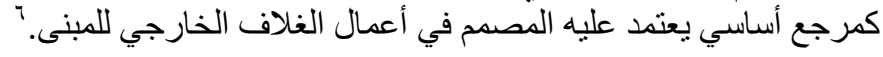

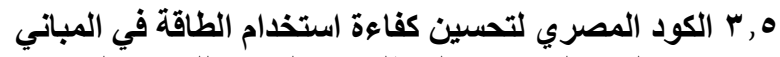

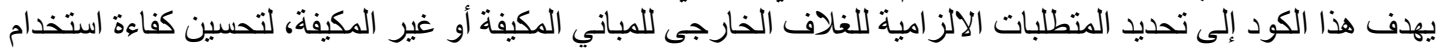

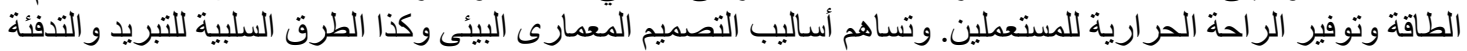

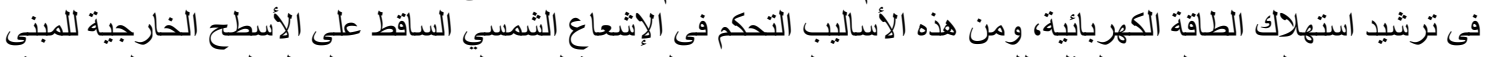

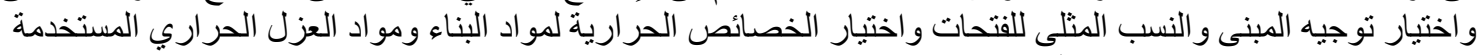
فى عزل الغلاف الخارجي للمبنى. 


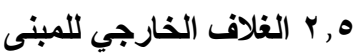

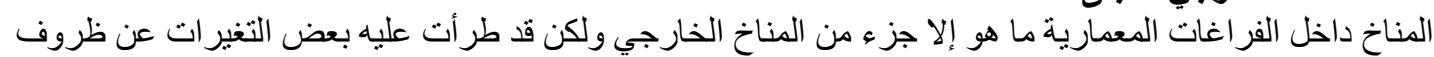

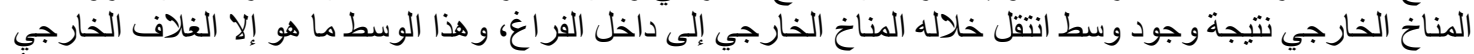

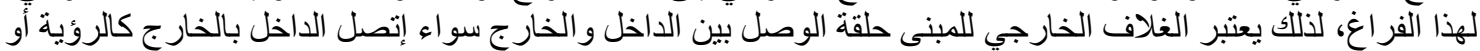

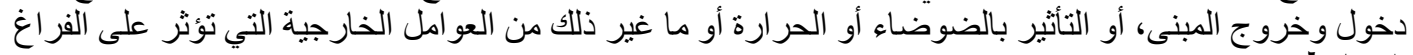

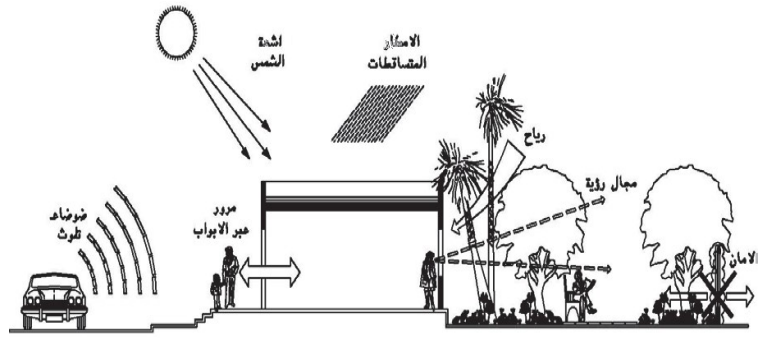

\section{تبادل الاتصال بين الداخل والخارج عن طريق الغلاف الخارجي}

ويعتبر الانتقال الحراري ما بين الداخل والخارج من أهم عناصر المناخ ذات التأثير القوي على الإنسان من حيث إحساسه

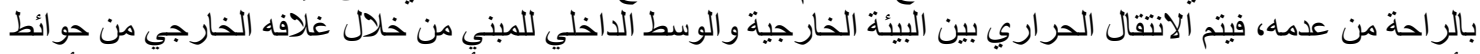

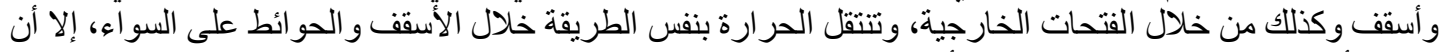

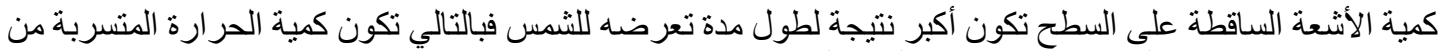

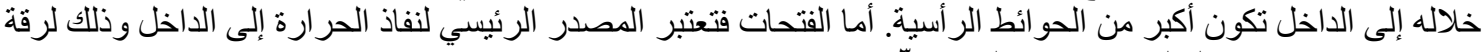

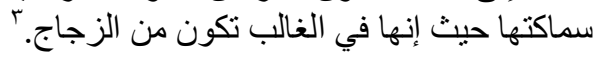

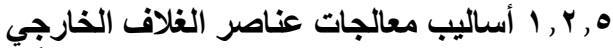

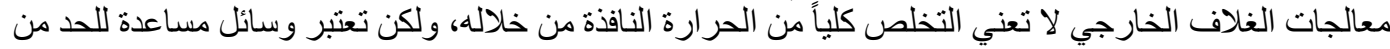

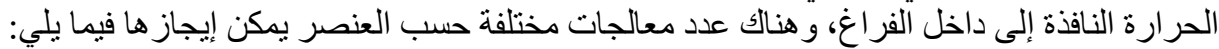

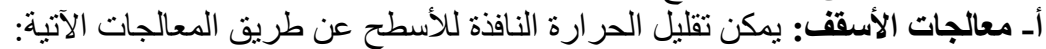

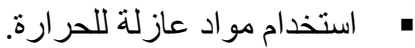

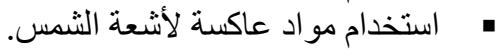

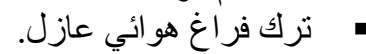

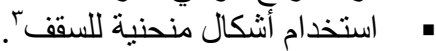
بـ معالجات الحوائط: تتشابه معالجات الحو ائط إلى حد كبير مع معالجات الأسقق ومن أمتلة تلك المعالجات كما يلي: • استخدام عازل للحر ارة في الحوائط.

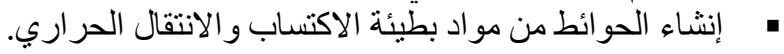

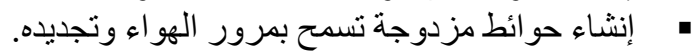

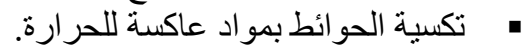
• تظليل أجزاء من الحو ائط الخارجية بالبروزات.

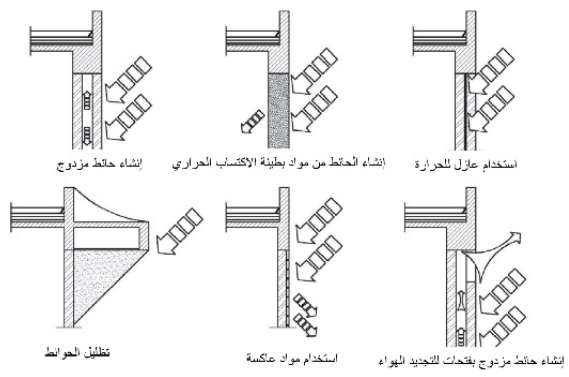

وسائل معالجات الحوائط 


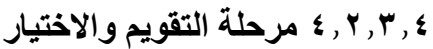
بما أن الحكم على الأفكار كان ممنو عاً خلال طر ح الأفكار، فمن المؤكد أن الأفكار الواردة في القائمة غبر ملائمة أو غير

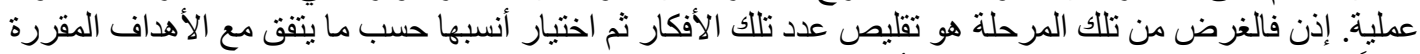
سابقاً، وتتكون عملية التقويم و الاختيار من أربع خطو التر كما يلي

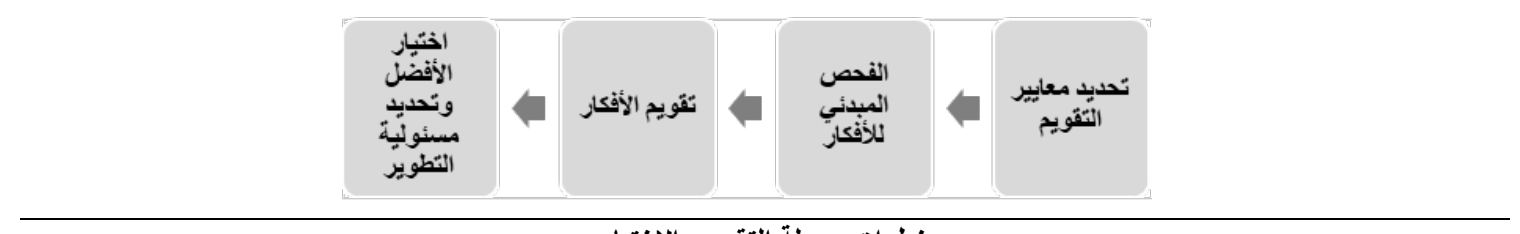

خطوات مرحلة التقويم والاختيار

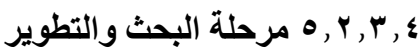

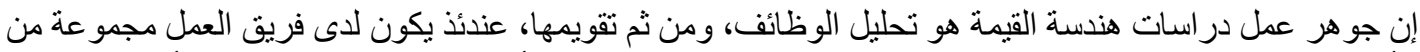

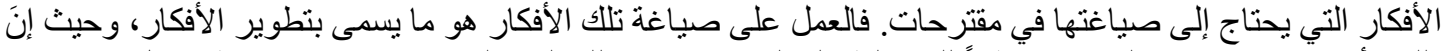

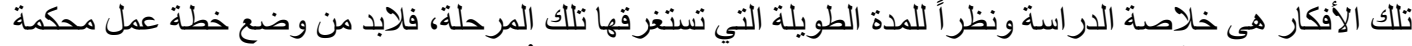

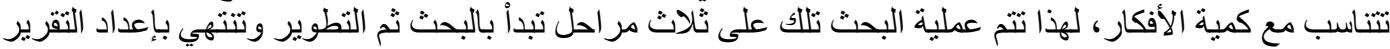

المبئي للار اسة.

•ـ المبنى والطاقة

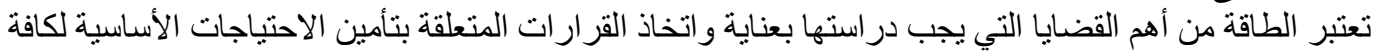

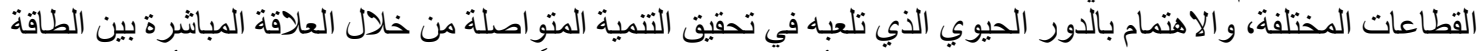

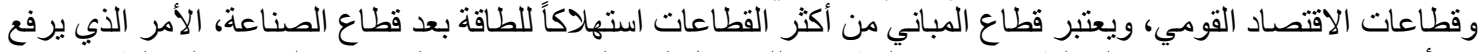

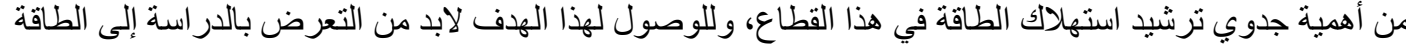
المستهلكة بالمباني ومو اضع ذند اللك الاستهلاك وتحديد مو اضع الهدر فيه.

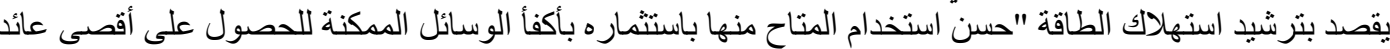

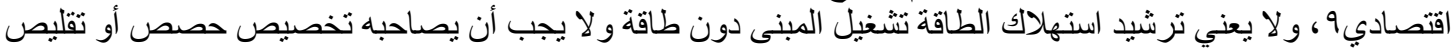

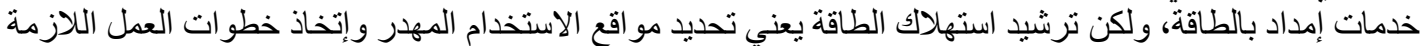

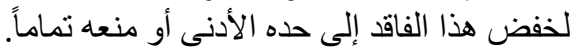

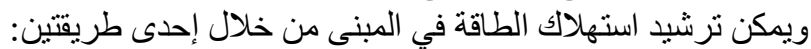

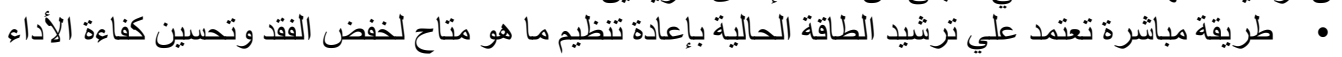
باستخدام النظم المرشدة للطاقة. • طريقة غير مباشرة وتعتمد على استبدال الطاقة الحالية بأخرى مستديمة أو أكثر كفاءة، باعتماد المبنى ذاتياً علي

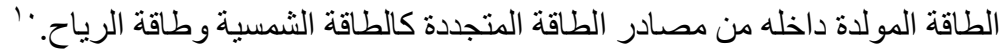

رئ 1 , 1 محاور ترشيا استهلاك الطاقة بالمباني

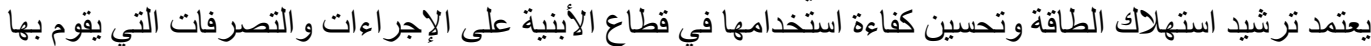

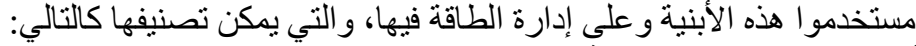

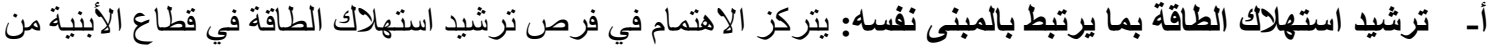

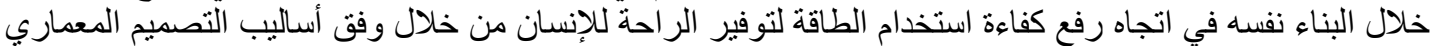

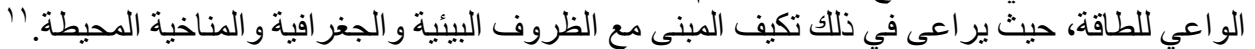

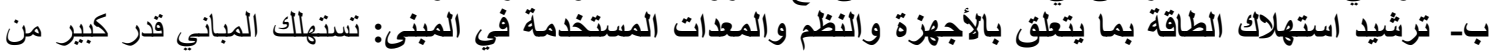

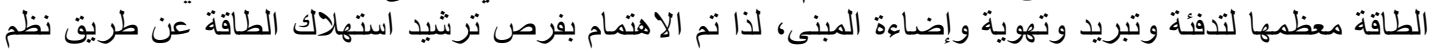

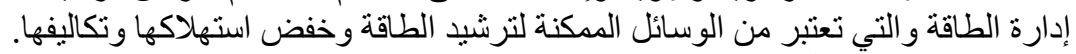

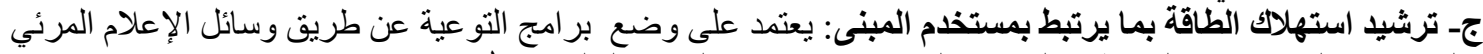

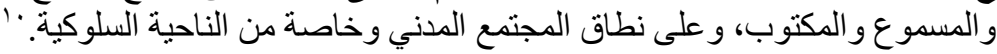


بهندسة القيمة، كما أنه لا يشترط أن يكون جميع أفر اد الفريق مهندسين، ولكن يجب أن يكون الفريق بقيادة أخصائي قيمي معتمد (Certified Value Specialist) (CVS)

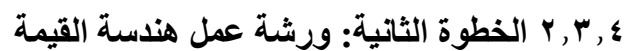

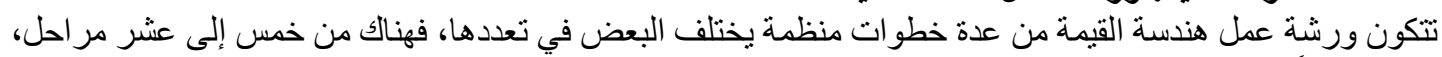

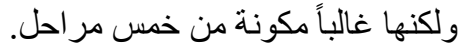
و وهو المتبع من قبل الكثير من خن خبر اء إدارة القيمة، و هذه المر احل متسلسلة منطقياً حيث يجب الانتهاء تماماً من أب مرحلة

قبل البدء في المرحلة التي تليها.

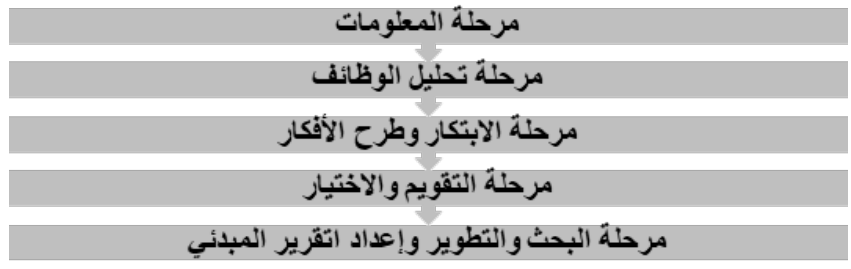

مراحل ورشة عمل هندسة القيمة

ع , r, r , أ مرحلة المعلومات

تهدف هذه المرحلة إلى تكوين القاعدة المعلوماتية الأساسية اللازمة للتصميم ومعرفة الاعتبار ات الأساسية عن فئة

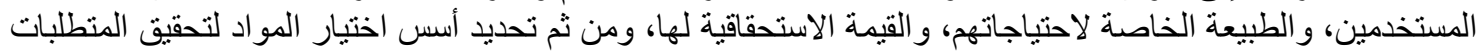

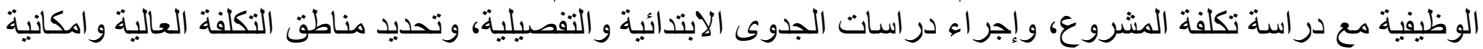

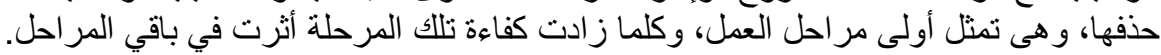

ع

إن مرحلة تحليل الوظائف هيى الركيزة الترة التي تعتمد عليها در اسات هندسة القيمة، و التي تميز ها على أساليب حل المشكلات

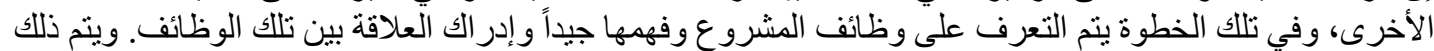

باتباع الخطو ات التالية

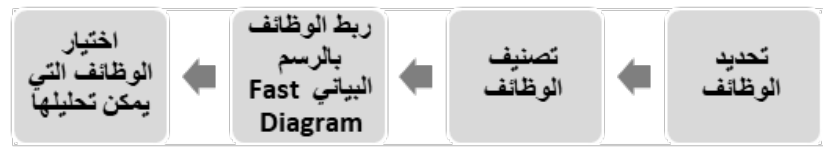

خطوات مرحلة تحليل الوظائف

أــ تحديد الوظائف: إن الوظيفة هى الغرض الذي أوجد من أجلها المنتج أو المشروع.

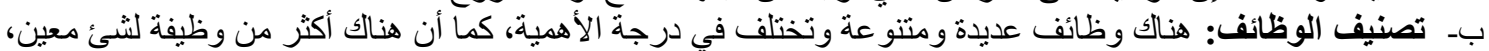

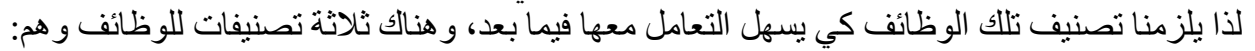

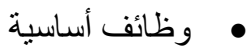
• • • • • م وظائف ثنانوية

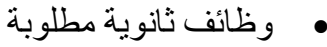

ج- ربط الوظائف برسم بياني (مخطط فاست) FAST Diagram: بعد تحديد الوظائف وتصنيفها بلزم ربط بعضها

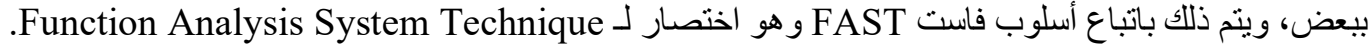
دـ اختيار الوظائف التي يمكن تحسينها: بناء على الوظائف التي تم تحديدها تلفي في نموذج (FAST) يكون لدينا فهم و إدراك

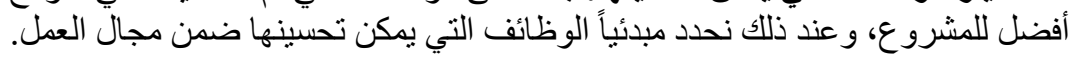

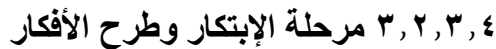

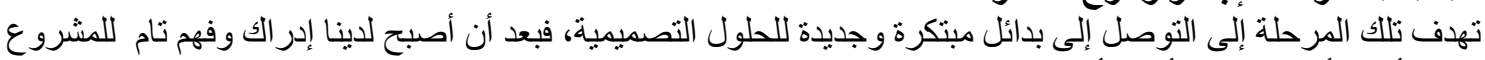

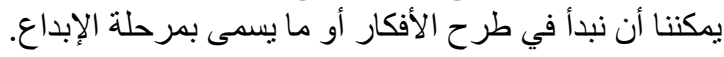


المقترحات. كل ذلك جعلها قادرة على تحسين العمل المعمارى و ابتكار الافكار المبدعة و الارتقاء بمستوى المشاريع

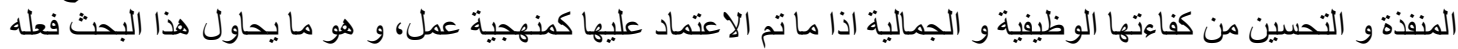

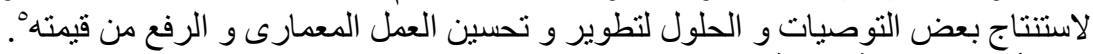

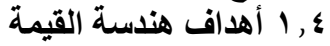

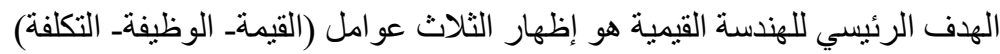

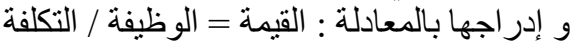

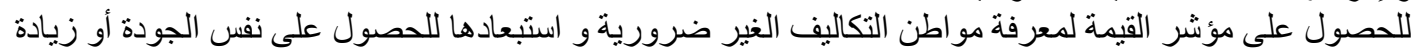

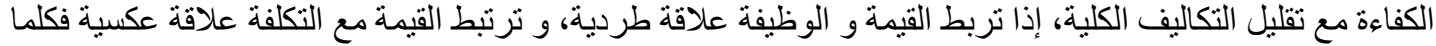

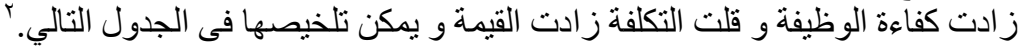

\begin{tabular}{|c|c|c|c|}
\hline فاعلية هندسة القيمة & التكلفة & الوظيفة و الجودة & \\
\hline \multirow{2}{*}{ أهداف هندسة القيمة } & إنخفضت & تطورت & 1 \\
\hline & ثُابتة & تطورت & $r$ \\
\hline \multirow{2}{*}{ مرفوض } & زادت & تطورت & $r$ \\
\hline & إنذفضت & إنخفضت & $\varepsilon$ \\
\hline
\end{tabular}

جدول ا : علاقة محاور هندسة القيمة

ع ب ب كيفية قياس القيمة

القيمة ترنكز على ثناثة عناصر رئيسية وهى التكلفة والجودة والأداء الوظيفي، وللحصول على مقياس حقيقي للقيمة لابد من أخذ جميع هذه العناصر بعين الاعنبار :

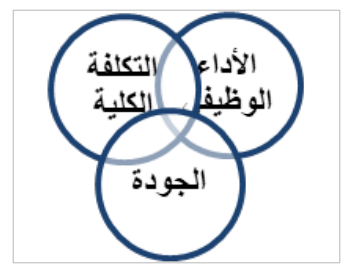

عناصر القيمة

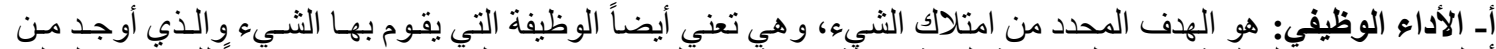

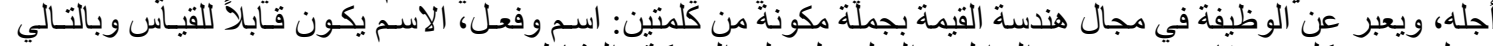

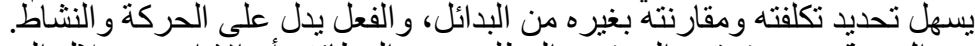

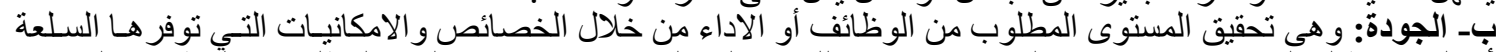

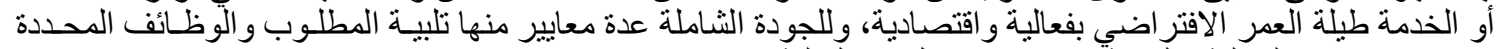

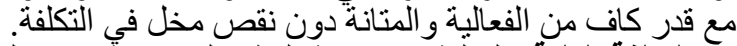

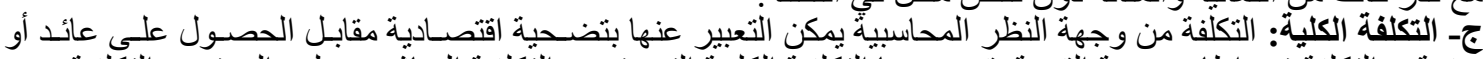

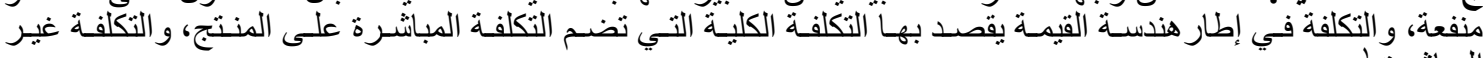
المبانشرة.

ع ب ب خطة عمل هندسة القيمة

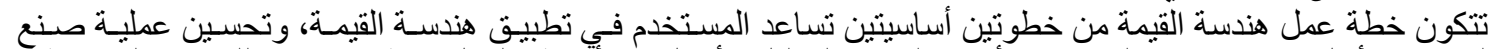
القرار من أجل عرضل جميع الحقائق والأفكار اللازمة لتحليل الأفعال وتبداً خطة العمل بخطوة الإعداد للار اسة يليها خطوة ورشة عمل هندسة القيمة. الإني

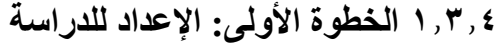

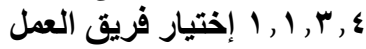

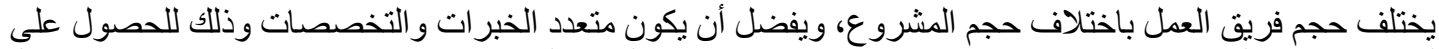

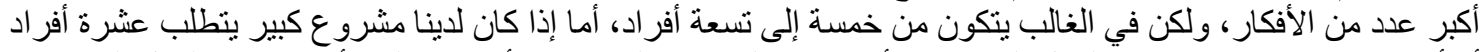

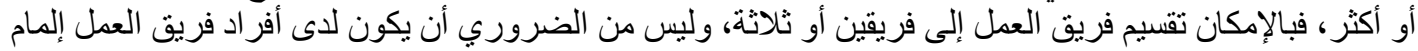




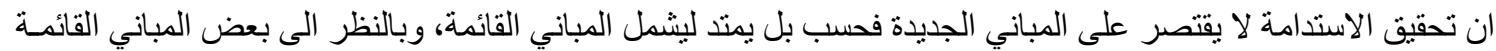

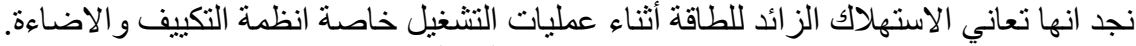

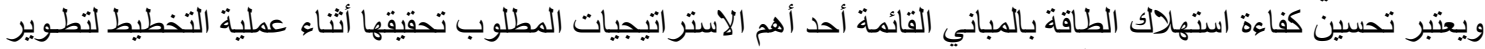

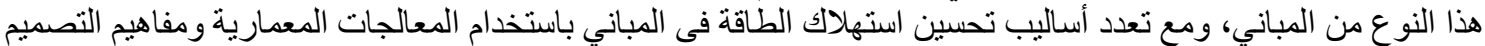

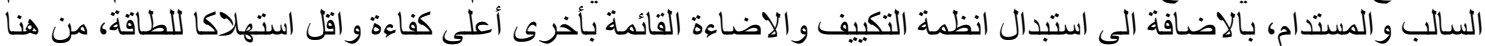

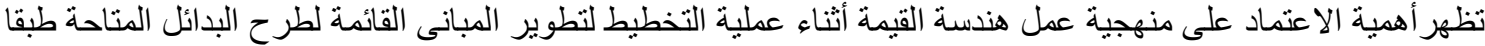

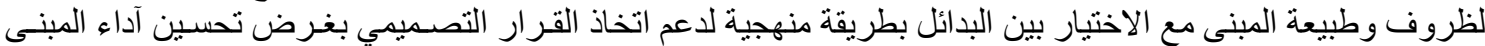
بأعلى جودة و أقل تكلفة.

\section{الكلمات المفتاحية : هندسة القيمة ,تحسين كفاءة استهلاك الطاقة بالمباني ,المباني المستدامة ,تخضير المباني القائمة.}

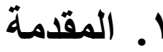

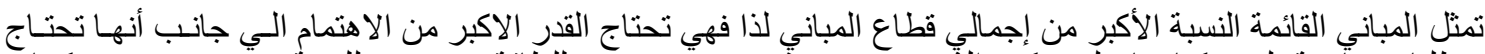

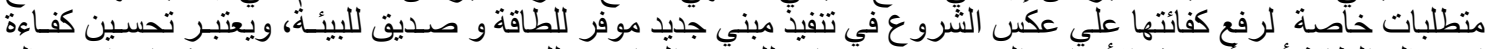

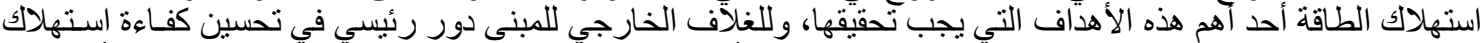

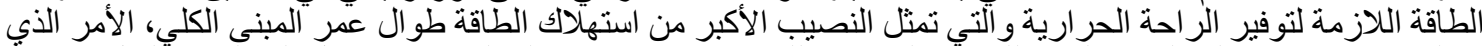

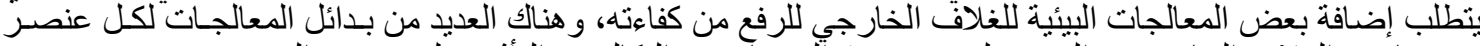

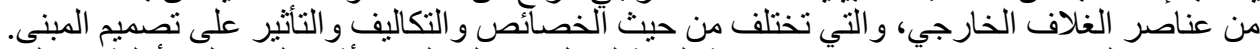

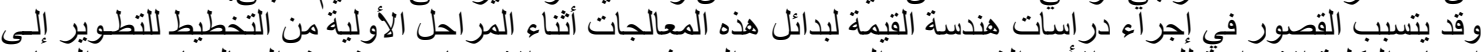

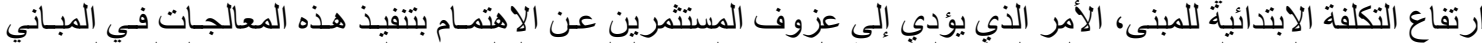

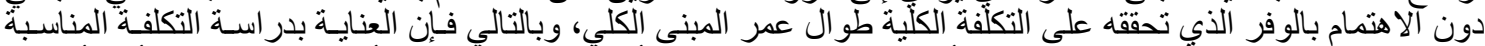

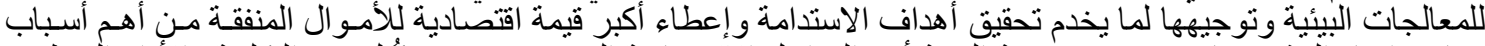

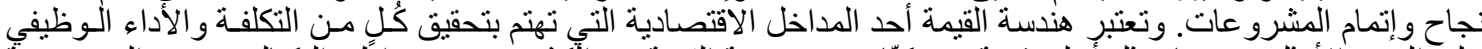

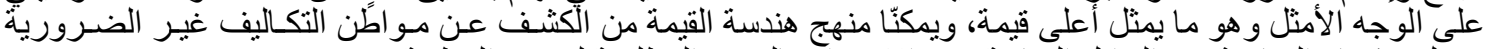

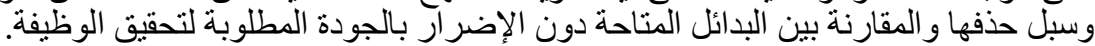

\section{r. أهداف البحث}

يهذف البحث الى وضع منهجية لعملية التخطيط لتطوير المباني القائمة تعتمد على تطبيق هندسة القيمة فى اتخاذ القرارات

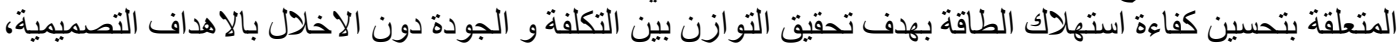

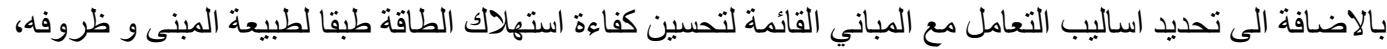

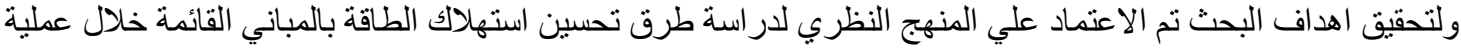

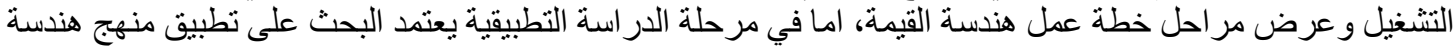
القيمة على المباني القائمة بهدف تحسين كفاءة الطاقة اللازمة للتشغيل اثناء عملية التخطيط للتطوير.

\section{بر فيات البحث}

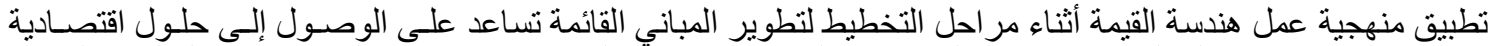

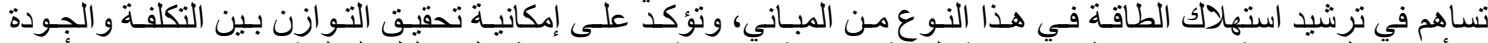

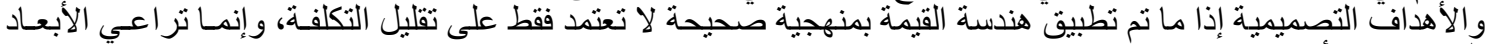

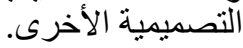

\section{؛. هندة القيمة}

تعتبر هندسة القيمة إحدى أهم المناهج الإدارية و أحدثها اعتماداً فى دول العالم، و هى در اسة تحليلية ذات منهج محدد، و و

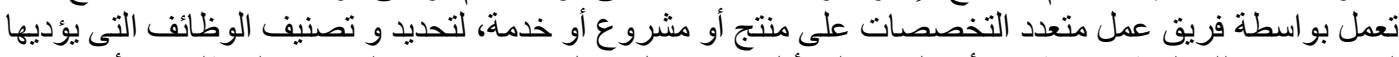

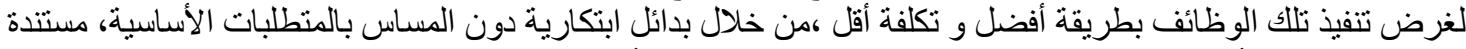

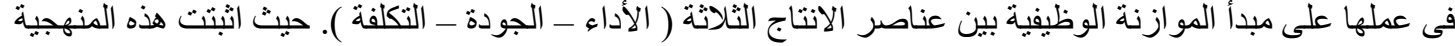

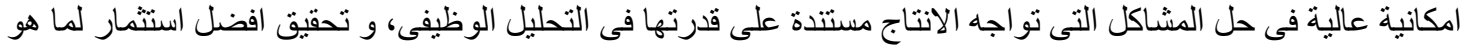

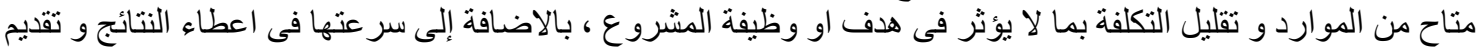


Vol.16, No. 60, July, 2021,893-909

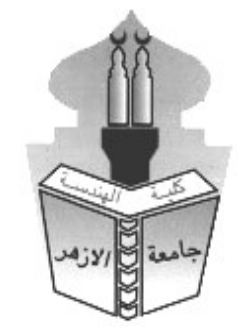

\title{
The Role of Value Engineering in Improving the Energy Efficiency of Existing Buildings
}

\author{
Mohamad Abdalraouf ${ }^{1, *}$, Ismail Mohamed ${ }^{1}$, Mohamed Zakaria Elders ${ }^{1}$ \\ ${ }^{1}$ Architecture Engineering Department, Faculty of Engineering, Al-Azhar University, Cairo, Egypt. \\ *Corresponding Author E-mail: mohamadabdalraouf@gmail.com
}

\begin{abstract}
The research study aims to develop existing buildings with a more sustainable vision, taking into account the application of sustainable design concept during the planning phase of development. Thinking about design process should be as an integrated system, where architectural side and passive design strategies can be integrated through development operations.

The different climatic conditions surrounding the building, which are determined by the region in which the building is located; the different orientation of each level of the outer casing relative to the main directions, and dividing the outer casing elements into solid and open, vary the treatment alternatives of each of these elements depending on the circumstances affecting it.

Thus, the value engineering approach gets its importance of its application to sustainable existing buildings. The project achieves the desired objectives through a methodology that helps to choose between these alternatives on a scientific that interests in studying cost, functionality and quality, which has started to be used as one of the assistance areas of the development process in order to reach a balance point between quality and costs. The objective of this research is to apply value engineering during the stages of existing building's development and its impact on the design decisions through an analytical study of the mandatory requirements of the outer casing of existing buildings to improve energy consumption, use the value engineering approach in comparison, choose among the available alternatives during work phases of the architectural project and take the decision which achieves the highest quality at the right cost.
\end{abstract}

KEYWORDS: Value Engineering - Improving Energy Efficiency in Buildings - Sustainable Buildings - Greening Existing Buildings

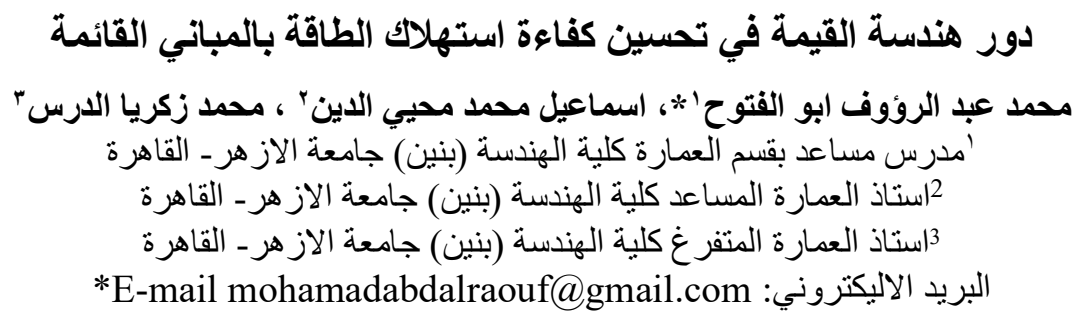

